\title{
Overview of participatory water management to overcome drought towards agricultural sector
}

\author{
Dian Tristi Agustini ${ }^{*}$, Johan Iskandar $^{2}$ \\ ${ }^{1}$ Environmental and Energy Management Program, University of Twente, The Netherlands \\ ${ }^{2}$ Postgraduate Program of Environmental Science and Research Staff at CESS, Padjadjaran University,
}

\begin{abstract}
Drought gives severe impact on agricultural system on fulfilling global food demands. Addressing the root causes of drought related to the community as water users can be done by combating illegal water extraction and controlling water supply. The discussion is based on information obtained from scientific literatures, such as Science Direct, Google Scholar and Scopus. From literature survey, participatory water management engage stakeholders harmonizing water supply and demand to tackle drought through water resources protection and efficient water use. Giving more power of people in the system impacts their better involvement in planning and decision-making processes. Top-down and bottomup participation models have different dynamics in water governance and both can be implemented based on the local contexts. Trade-offs and dilemmas should be considered in order to produce an effective participation. Collaboration and good communication among water users result in a better water management.
\end{abstract}

\section{Inttroduction}

Drought described as a lack of water availability because of low input from precipitation and high output from evapotranspiration which occur on several months to years that affects societal life[1],[2]. Van Loon et al., (2016) stated, drought can be caused by human. When humans do over extraction of nature to fulfill their desires, complex social-ecological problem will be generated like drought [3]. Drought also occurs naturally and it is divided two kinds of drought, meteorological drought and hydrological drought [4]. Meteorological drought occurs when precipitation is decreasing or temperature is increasing. When those changes influence the hydrologic system such as decreased runoff and soil moisture, hydrological drought occurs. Subsequently, meteorological drought will be more frequent as climate continues to change. It creates stress on watersheds and increases hydrological drought. This situation brings disruption on water resources as well as its supply to human and other living things. Van Loon et al. (2016) explained that human's population grows rapidly and water demands are getting increase because of their desires on using water. At the same time, when drought meets this condition, acute water shortage will be resulted. To date, drought become more frequent due to climate change based on temperature, rainfall duration, and land cover change [4],[5],[6],[7].

Agricultural system depends on sufficient irrigation to fulfill global food demand. Lack of water due to drought brings serious negative impacts on the system. It influences crop yield and also leads to crop failure.
Subsequently, severe socio-economic impact can be resulted. Smallholders are prone to face this condition. They have lack of budget to improve their technology on irrigation system. To reduce water consumption, farmers can adopt adaptation strategy, based on scientific research, by changing their cropping pattern [5], for instance, mixed farming of sugarcane and cassava in Northeast Thailand[8]; intercropping by selecting certain types of soybeans in East Java Indonesia [9]; planting wheat-maize-soybean in upland summer while double rotation of paddy and potato in rainy season in a hilly area, Sichuan Province, China [10]. In this regard, farmers need strong connection and support from others, for instance, local government at regional level in providing meteorological data and also early warning system [11]; higher government level in technical and financial support on developing irrigation infrastructure and advanced technology collaborating with private sectors and local experts.

Participatory water management as an adaptation strategy tackles drought by co-working with diverse actors such as scientists, water manager, authorities, and water users[12]. Addressing drought from its root cause is started by managing water users from unauthorized water withdrawn[1]. Water users consist of organizations, farmers and households that have a common interest to exploit water. Having feedbacks from water users as a part of social system and water withdrawal as physical system are important on drought period [2]. The main success in managing water depends on active cooperation and coherent behavior of community, government at national and local level, and

* Corresponding author: dian19005@mail.unpad.ac.id 
other parties by sharing information, consultation and involvement of water users [13] .

\section{Material and Methods}

All information in this article was collected from scientific literature databases such as Science Direct, Google Scholar, and Scopus to compile measures creating participatory water management related to drought in the agricultural sector. Firstly, it was started by compiling articles to gain information that explains the importance of community engagement and their active participation in water management. Secondly, the authors described two common models of participation and also their strengths and weaknesses. Lastly, technical processes are discussed for addressing drought which relates to farmers as the main actor of water users.

\section{Result}

\subsection{Participation Expectation}

Participation combines multi-actor perspectives through deliberation for finding solutions of particular issues. Participation creates more spaces for community to address unbalance roles in decision-making processes and they can be their own master from their selfgovernance [14]. Moreover, it strengthens community's capacity and helps them to get better fulfilment of their needs generally. The presence of participation in management is expected to increase its efficiency by involving interested parties or establishing an independent community for policy making [15]. Baker \& Chapin (2018) stated participation results two arguments, instrumental arguments which support policy process; and normative arguments as it increases democracy values, better social movements, and innovative political practices.

Unsuccessful participation might happen due to some weaknesses such as failure on stakeholder engagement comes from a limited role and less active involvement in a weak collaborative workplace. These are caused by inadequate of knowledge sharing, defining risk and solution [16]. When inclusivity in each process of participation and the same portion of stakeholder roles are available, people empowerment will be valuable and sustainable; in contrast, when there is no sufficient roles and rights on the marginal scales or weaker groups, it risks to reinforce inequalities [17].

\subsection{Ladder of Citizen Participation}

They are eight types of participation based on the ladder of citizen participation in Arnstein's concepts in 1969 [18]. Those are manipulation, therapy, informing, consultation, placation, partnership, delegation, and citizen control. In the first level of participation, which consists of the two-lowest ladder "manipulation" and "therapy", community participation is not exist and some parties discourage participation action but it does not lead to dispute [19]. Kotus \& Sowada (2017) mentioned the next level which is called tokenism, when deliberate just as symbolic action. This level includes "informing", "consultation" and "placation". Lastly, the highest level of participation is called citizen power because the community has a major role in the formal decision-making body over a certain program. It applies to "partnership", "delegation" and "citizen control". This ladder participation shows power shared in the community. The more power community has in the system, the more involvement they have in planning and decision-making processes.

Participatory water management engages stakeholders such as governments, water managers, scientists, community, private sectors, NGOs, and other interested parties to collaborate by giving their views to define issues and find solutions transparently on managing water supply and demand [20]'[21]. Sufficient knowledge should be owned by the community to understand the complexity of the problems. Mutual learning from knowledge sharing enhances collaborative networking and active involvement. Educating the community increases their engagement and their capacity for policymaking because it influences people's behavior in participatory processes in order to be more effective and efficient [14], [22].

\subsection{Top down and bottom up approach}

Commonly, there are two kinds of participation model, top-down and bottom-up. The top-down approach is a participation model which is derived from government programs and related to policy implementation [23]. Top-down approach recognizes the value of people's involvement in water management [24]. According to Van Buuren et al. (2019), in this system, the government has more roles for conducting capacity building to increase public awareness of environmental issues and to educate them about the current situation and its expectations. Van Buuren et al. (2019) stated, participation model can be conducted to fulfill legal frameworks and rules compliance only, and it is limited to the minimum required level. In this regard, government-led participation occupies the lower rungs of Arnstein's ladder. It brings some obstacles especially in decision-making process because of less involvement, lack of shared information to the community and insufficient stakeholder input, and it leads to consultation fatigue [25]. Local government should define regulation on community rights and roles. Having incentives might help to engage more people to join participation on water management, but it should be analyzed whether it affects people's behavior on managing water positively or not.

Additionally, van Buuren et al. (2019) stated bottom-up participation as a spontaneous response of the community that might come from the dissatisfaction of local authorities. It is triggered by a controversial policy process initiated by public authorities responding to specific needs in the local community. In bottom-up initiatives, local partners become vital for governments in planning, management, and also implementation processes, including operation and maintenance[23]. Thus, government and community should have an equal 
relationship to develop the governance capacity to solve public issues effectively and transparently[23]. Public authorities trust their partners using this empowerment to contribute values they want to pursue. However, it is inconceivable that the transfer of resources could go against public programs, or to develop counterinitiatives, assisted by the expertise and resources of the authorities [23].

\subsection{Interaction of public authorities and participants}

Van Buuren et al. (2019) and Basco-Carrera, Warren, van Beek, Jonoski, \& Giardino, (2017) showed that arrangement and engagement are crucial in building participatory forums. Arrangement relates to policies, rules, beliefs, and other agreements. These are influenced by knowledge, scientific and factual information from diverse actors participating in water management. Subsequently, once people have the same mindset and understanding about current environmental issues such as what drought is, which behavior may affect, and how to tackle this issue; it is easier for them to do further steps such as defining roles, policies, strategies, and technical practices in implementation. Preventing discrimination and maintaining openness in these steps bring good outcomes and people's satisfaction.

\subsection{Trade-offs and benefits}

On one hand, van Buuren et al. (2019) indicated problems and trade-offs in participatory management was possible to emerge and affect the running processes. Firstly, government programs have a certain time schedule and budget allocation, in contrast, linking opinions through working together with diverse stakeholders consumes more time. Jiménez et al., (2019) mentioned that participation bind to the commitments instead of antagonistic conditions. Direct decisions should be considered in order to avoid non-compliance with legal requirement regarding time allocation. Furthermore, organizing participation in proper ways can reduce conflict as well as proper time management. Secondly, finding relevant feedbacks to fulfill their desire needs more time as well. Publicity and education in a simple way can tackle these problems [26]. These improve awareness and also engage people participating in solving certain issues through promotion of water preservation and climate change in schools and public amenities facilitated by NGOs, and also providing incentives for water efficiency programs. Lastly, citizen control is built through fair participation with equality and balance power among actors in different scales and sectors. This is manifested throughout giving greater roles to local people especially in marginalized area for managing their own public services. Capacity building quite important to ensure they have sufficient knowledge for making crucial decisions.

On the other hand, Jingling et al. (2010) explained that effective participatory water management provided many benefits for human life. It can increase the competence and capability of local stakeholders regarding environmental awareness and technical issues in water management. Jiménez et al. (2019) emphasized that opportunities to have this particular knowledge developed confidence in community. Jingling et al. (2010) added that various kinds of information from people involved in management, who come from different levels and sectors, define conflicts between the water resource environment and its users. Therefore, good decisions are generated while creating sustainable management of services and resources.

\subsection{Conducive atmosphere and water management processes}

Character, mindset, interest, and need of stakeholders influence management process and its effectiveness [21]. To binding these, a transparent system, knowledge sharing, and mutual respect available in practice. Apart from that, each party will be selfish in fulfilling their need with limited resources. Hence, the sustainability of water resources should be prioritized and included in their policy on drought issue.

Policy can be as identification upon certain issues and their solutions referred to local environment description, including several steps such as formulation, adoption, implementation, and also monitoring and evaluation [21],[20]. Understanding more about the local conditions, policy planning can be based on indigenous knowledge and local skills, in terms of formulation, to increase sustainability of the policies [21].

Policy of water management for drought problems adopts measures regarding harmonization between water supply and demand [27]. In water demand, policy measurement includes incentive promotion, strategy of water infrastructure improvement for agricultural irrigation, preventing leakage, and tariff management areas and aquifers. Additionally, policy measures for water supply relates to how to solve the problem in environmentally friendly ways such as upgrading current infrastructures, rejuvenation of water resources, and enlargement of natural catchment [27].

Moreover, Stein et al. (2016) stated, regarding policy implementation, stakeholders establish drought management plant for reducing drawbacks on the economy, social and environment. It covers all water demand including estimation of the untapped potential such as agriculture, local entrepreneurial activities and other possibilities. Improvement of water efficiency, in this case, is prioritized before undertaking water supply for water use as little as possible. This management includes water pricing determination to make people use water efficiently and also provide them incentives.

Water supply system relates to natural resources preservation and environmentally friendly strategies [27]. Climate change influences water resources regarding the reduction of dissolved oxygen concentration because of high temperature; and water resource degradation relates to the increase of extreme weather events[28]. Stein et al. (2016) explained, beside climate change impact, water resources disruption is caused by land-use change and socio-economic 
development. Dealing with these, spatial planning should be in harmony with water management due to its impacts on both water quality and water quantity. To reduce environmental damage, land and water use adjust water levels. Other ways of increasing water supply are conservation of water resources by retaining water surface as much as possible and flow it naturally in catchment area which also give benefit to biodiversity especially in aquatic ecosystem; development storage capacity of the resources; improving infrastructures such as bridges, dikes, and dams for connectivity and water distribution.

Lastly, according to Stein et al. (2016), the sustainability of participatory water management needs evaluation of its management by providing means to measure the successes and failures of the water management implementation. Water monitoring depends on applied technology for checking water availability and water quality supported by specified competencies of actors, for instance experts from local institutions or governments. Accurate and actual data resulted to portrait the water quantity and water quality. Monitoring also covers the achievement of the goals which decided by stakeholders earlier and also about the participation processes. Grafton et al. (2019) summed up evaluations of water management such as provide strengths and weaknesses of the management not only in local scale but also from broader scale as a long term effect, updating new information, changes in unknowable factors; always maintain engagement through discussion and communication between stakeholders.

\section{Discussion}

When participatory water management can gain many people from interested sectors to engage with a balance role, it will be perfect for policymaking in equitable manner. Yet, adequate time and money are needed to tackle obstacles and challenges in implementation. Conflict among actors in management might emerge frequently. Moreover, waiting for effective feedbacks and creating balance resources through knowledge sharing and mutual learning is time consuming as well. Thus, time and budget allocation should be defined very well by stakeholders. Experiencing in creating participation, like learning from the past, also help to exteriorize successful participatory water management.

Creating participation with a top-down model has a positive impact on people's knowledge. Based on Macura et al. (2016), it creates a short-term positive impact and weak collaboration. Participation, that is driven by the government, affects people's education but not on changing people's behaviour. This model is also costly because money spent on people's intention of getting incentives only and it does not meet the desired goals. In contrast, bottom-up model comes from community interest to encourage policy innovation[29]. To shape ideas and wisdom from various local people are difficult, but it builds a strong bond among people of ownership of resources and creates better management. In this regards, to choose one of them or combining both models should consider their strengths and weaknesses and build upon the local context. Openness to engage participation and trust of each other should be maintained in every process.

A study case regarding farmer participation in irrigation system in Rancaekek Sub-district, Bandung District, West Java Province, Indonesia, revealed that humans, as water users, had the main effect on water management, instead of method, money, machine and material [30]. It applied a top-down participation model, created by water authority on state-level which coordinated by local government. The level of farmer participation was high, linking to data which mentioned that initiative was the main reason farmers joining participatory water management. Good communication and mutual assistance among farmers or groups regarding irrigation were the success factor of participation. Lesson learned from this example is that water management for agriculture has closed connection to stakeholders and collaboration as well as good communication among them result in better water management.

\section{Conclusion}

Water management, to address drought in agriculture, has a closed connection to stakeholders. Collaboration and good communication among them result in a better water management. Participation, whether top-down or bottom-up model, strengthens people on their knowledge and values. It allows people from different sectors and scales to work together linking their notions to manage water supply and demand in order to prolong the availability of the water resources and fulfill socioeconomical needs. Solutions of drought problems are conducted through harmonization of water supply and water demand. Water supply connects to ecological system improvement and preservation such as water resources protection, land use management and improvement of infrastructures for better connection and distribution. Moreover, water demand is about mapping all water needs, improving water use efficiency by leakage detection using technology and innovation; implementing water pricing management for environmental and economic benefit. Monitoring and evaluation for the sustainability of participatory water management are conducted by certain means and scientific knowledge and defining strengths and weaknesses of each process.

\section{Acknowledgement}

This research is supported by the Ministry of National Development Planning, Republic of Indonesia.

\section{References}

1. A. C. S. Silva, C. O. Galvão, and G. N. S. Silva, "Droughts and governance impacts on water scarcity: An analysis in the Brazilian semi-arid," IAHS-AISH Proc. Reports, vol. 369, no. 2004, pp. 129-134, (2015). 
2. A. F. Van Loon et al., "Drought in a humanmodified world: Reframing drought definitions, understanding, and analysis approaches, " Hydrol. Earth Syst. Sci., vol. 20, no. 9, pp. 3631-3650, (2016).

3. L. P. Crevier and L. Parrott, "Synergy between adaptive management and participatory modelling: The two processes as interconnected spirals, ” Ecol. Inform., vol. 53, no. May, p. 100982, (2019).

4. A. Hein, L. Condon, and R. Maxwell, "Evaluating the relative importance of precipitation, temperature and land-cover change in the hydrologic response to extreme meteorological drought conditions over the North American High Plains, ” Hydrol. Earth Syst. Sci. Discuss., pp. 130, (2018).

5. IPCC, “Global Warming of $1.5^{\circ} \mathrm{C}$. An IPCC Special Report on the impacts of global warming of $1.5^{\circ} \mathrm{C}$ above pre-industrial levels and related global greenhouse gas emission pathways, in the context of strengthening the global response to the threat of climate change," (2018).

6. L. S. Sifundza, P. van der Zaag, and I. Masih, "Evaluation of the responses of institutions and actors to the 2015/2016 el niño drought in the komati catchment in Southern Africa: Lessons to support future drought management, " Water SA, vol. 45, no. 4, pp. 547-559, (2019).

7. Z. Zeng, W. Wu, Z. Li, Y. Zhou, and Y. Guo, “Agricultural Drought Risk Assessment in," no. 22 May 2019, pp. 1-20, (2019).

8. K. Yoshida, M. Srisutham, S. Sritumboon, D. Suanburi, and N. Janjirauttikul, "Weather-induced economic damage to upland crops and the impact in Thailand.pdf," no. 30 March 2019, pp. 341349, (2019).

9. A. Harsono, D. A. A. Elisabeth, S. Muzaiyanah, and S. A. Rianto, "Soybean-maize intercropping feasibility under drought-prone area in East Java, Indonesia, " Biodiversitas, vol. 21, no. 8, pp. 3744-3754, (2020).

10. Y. Zhang, H. Qu, X. Yang, M. Wang, N. Qin, and Y. Zou, "Cropping system optimization for drought prevention and disaster reduction with a risk assessment model in Sichuan Province," Glob. Ecol. Conserv., vol. 23, p. e01095, (2020).

11. E. Makaya et al., "Water governance challenges in rural South Africa: Exploring institutional coordination in drought management, " Water Policy, vol. 22, no. 4, pp. 519-540, (2020).

12. W. S. Júnior et al., "Water: Drought, crisis and governance in australia and brazil," Water (Switzerland), vol. 8, no. 11, pp. 1-21, (2016).

13. M. Graversgaard, B. H. Jacobsen, C. Kjeldsen, and T. Dalgaard, "Stakeholder engagement and knowledge co-creation in water planning: Can public participation increase cost-effectiveness?," Water (Switzerland), vol. 9, no. 3, pp. 1-29, (2017).
14. L. Mellinger and D. Floriani, "Democratic participation in the management of common natural resources and the native populations in the Southern Coast of Paraná," Ambient. e Soc., vol. 18, no. 2, pp. 1-22, (2015)

15. S. Baker and F. S. Chapin, "Going beyond 'it depends:' the role of context in shaping participation in natural resource management," Ecol. Soc., vol. 23, no. 1, (2018).

16. M. Graversgaard, M. H. Thorsøe, C. Kjeldsen, and T. Dalgaard, "Evaluating public participation in Denmark's water councils: How policy design and boundary judgements affect water governance!," Outlook Agric., vol. 45, no. 4, pp. 225-230, (2016).

17. A. Jiménez et al., "The enabling environment for participation in water and sanitation: $A$ conceptual framework, "Water (Switzerland), vol. 11, no. 2, pp. 1-21, (2019).

18. M. B. Guaraldo Choguill, "A ladder of community participation for underdeveloped countries, " Habitat Int., vol. 20, no. 3, pp. 431-444, (1996).

19. J. Kotus and T. Sowada, "Behavioural model of collaborative urban management: extending the concept of Arnstein's ladder, ' Cities, vol. 65, pp. 78-86, (2017).

20. R. Q. Grafton, D. Garrick, A. Manero, and T. N. Do, "The water governance reform framework: Overview and applications to Australia, Mexico, Tanzania, U.S.A and Vietnam, ” Water (Switzerland), vol. 11, no. 1, (2019).

21. L. Basco-Carrera, A. Warren, E. van Beek, A. Jonoski, and A. Giardino, "Collaborative modelling or participatory modelling? A framework for water resources management," Environ. Model. Softw., vol. 91, pp. 95-110, (2017).

22. J. Krywkow, “A Methodological Framework for Participatory Processes in Water Resources Management, " University of Twente, (2009).

23. A. van Buuren, I. van Meerkerk, and C. Tortajada, "Understanding emergent participation practices in water governance, ” Int. J. Water Resour. Dev., vol. 35, no. 3, pp. 367-382, (2019).

24. B. Macura, L. Secco, E. Pisani, A. S. Pullin, and V. Reyes-García, "All that glitters is not gold: the effect of top-down participation on conservation knowledge, attitudes and institutional trust in a Central Indian tiger reserve, ” Reg. Environ. Chang, vol. 16, pp. 125-140, (2016).

25. E. Hassenforder, D. Clavreul, A. Akhmouch, and N. Ferrand, "What's the middle ground? Institutionalized vs. emerging water-related stakeholder engagement processes, ” Int. J. Water Resour. Dev., vol. 35, no. 3, pp. 525-542, (2019).

26. L. Jingling, L. Yun, S. Liya, C. Zhiguo, and Z. Baoqiang, "Public participation in water resources management of Haihe river basin, China: The analysis and evaluation of status quo," 
Procedia Environ. Sci., vol. 2, no. 5, pp. 17501758, (2010).

27. U. Stein, G. Özerol, J. Tröltzsch, R. Landgrebe, A. Szendrenyi, and R. Vidaurre, "European Drought and Water Scarcity Policies," in Governance for Drought Resilience, H. Bressers, B. Nanny, and C. Larrue, Eds. Springer, (2016).

28. UNESCO, "The United Nations World Water Development Report 2020 executive summary: Water and climate change," Perugia, (2020).

29. J. Ouyang, K. Zhang, B. Wen, and Y. Lu, “Topdown and bottom-up approaches to environmental governance in China: Evidence from the river chief system (RCS), ” Int. J. Environ. Res. Public Health, vol. 17, no. 19, pp. 1-23, (2020).

30. I. Ardiansah, R. B. N. Wargadibrata, C. Asdak, D. M. Rahmah, and S. H. Putri, "Partisipasi Petani Terhadap Pengelolaan Air Irigasi Di Kecamatan Rancaekek, Kabupaten Bandung, Provinsi Jawa Barat," J. Sains dan Teknol. Ind., vol. 16, no. 1, p. 7, (2018). 